\title{
BMJ Open Does family-centred neonatal discharge planning reduce healthcare usage? A before and after study in South West England
}

Jenny C Ingram, ${ }^{1}$ Jane E Powell, ${ }^{2}$ Peter S Blair, ${ }^{1}$ David Pontin, ${ }^{3}$ Maggie Redshaw, ${ }^{4}$ Sarah Manns, ${ }^{2}$ Lucy Beasant, ${ }^{1}$ Heather Burden, ${ }^{5}$ Debbie Johnson, ${ }^{1}$ Claire Rose, ${ }^{6}$ Peter J Fleming ${ }^{1}$

To cite: Ingram JC,

Powell JE, Blair PS, et al. Does family-centred neonatal discharge planning reduce healthcare usage? A before and after study in South West England. BMJ Open 2016;6: e010752. doi:10.1136/ bmjopen-2015-010752

- Prepublication history for this paper is available online To view these files please visit the journal online (http://dx.doi.org/10.1136/ bmjopen-2015-010752).

Received 4 December 2015 Revised 30 December 2015 Accepted 18 January 2016

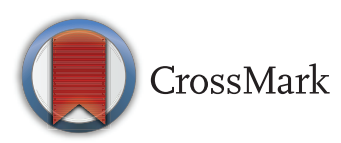

For numbered affiliations see end of article.

Correspondence to Dr Jenny C Ingram; jenny.ingram@bristol.ac.uk

\section{ABSTRACT}

Objective: To implement parent-oriented discharge planning (Train-to-Home) for preterm infants in neonatal care.

Design: Before and after study, investigating the effects of the intervention during two 11-month periods before and after implementation.

Setting: Four local neonatal units (LNUs) in South West England.

Participants: Infants without major anomalies born at 27-33 weeks' gestation admitted to participating units, and their parents.

Train-to-Home intervention: A family-centred discharge package to increase parents' involvement and understanding of their baby's needs, comprising a train graphic and supporting care pathways to facilitate parents' understanding of their baby's progress and physiological maturation, combined with improved estimation of the likely discharge date.

Main outcome measures: Perceived Maternal Parenting Self-Efficacy (PMP S-E) scores, infant length of stay (LOS) and healthcare utilisation for 8 weeks following discharge.

Results: Parents reported that the Train-to-Home improved understanding of their baby's progress and their preparedness for discharge. Despite a lack of change in PMP S-E scores with the intervention, the number of post-discharge visits to emergency departments (EDs) fell from 31 to 20 ( $p<0.05)$, with a significant reduction in associated healthcare costs ( 33400 to $£ 2200 ; p<0.05)$ after discharge. In both study phases, over $50 \%$ of infants went home more than 3 weeks before their estimated date of delivery (EDD), though no reduction in LOS occurred.

Conclusions: Despite the lack of measurable effect on the parental self-efficacy scores, the reduction in ED attendances and associated costs supports the potential value of this approach.

\section{INTRODUCTION}

The improvements in survival of preterm infants over the past 20 years mean that

\section{Strengths and limitations of this study}

- This is the first study to measure the impact of a neonatal family-centred care intervention on parental self-efficacy or use of emergency department (ED) post-discharge for moderately preterm infants.

- Health economic data collection was available for most families which facilitated a detailed analysis of the costs of healthcare usage following discharge.

- The lack of time for implementing the Train-to-Home intervention meant that some staff were not confident in using the familycentred approach to discharge planning.

- The quasi-experimental study design (before and after) was also a limitation in that the changes in outcome measures were not randomised between units, but there were no significant differences in the infant or maternal demographics between the two study periods.

more than $90 \%$ of infants born at 27 weeks' or more gestation will survive to go home. ${ }^{1}$ For most infants, a relatively short period in a neonatal intensive care unit (NICU) will be followed by a longer period in high dependency and then special care before discharge home. ${ }^{2}$

Parents of preterm infants need to learn how to care for them after discharge home, and to prepare themselves and their home environment. Evidence suggests that ex-preterm infants make a disproportionate demand on emergency and 'out-of-hours' health services. ${ }^{3}{ }^{4}$ Parents have particularly expressed concern and uncertainty about how best to respond to minor illness or changes in routine for their babies. ${ }^{56}$

A structured approach to discharge planning using care pathways and predictable 
timings for discharge improves the quality of care before and after discharge and reduces the need for unexpected re-admission after discharge, as well as improving patient satisfaction. ${ }^{7} 8$ Parent-focused or family-centred neonatal care involves providing accurate information, and individualised care, including parents in infant care, and promoting positive relationships with staff. ${ }^{9} 10$

Many parents of preterm infants are routinely informed by neonatal staff that their baby will be discharged home at or around the time the baby was due to be born-that is, the estimated date of delivery (EDD). This continues despite increasing evidence that improvements in neonatal care over recent years have led to shorter stays in hospital and earlier discharge to home. ${ }^{11}$ Using EDD as the expected discharge date means that, in many neonatal units, the process of preparing parents to take their baby home is often left until shortly before the baby is to be discharged. Many parents feel unprepared as a result and lack confidence to care for their baby. ${ }^{612} 13$

In an audit of the length of stay (LOS) of preterm infants in local neonatal units (LNUs; as defined by the UK Department of Health) ${ }^{2}$ in the Southwest region from 2011 to 2013, we found that almost all infants born at 27-33 weeks' gestation were discharged home well before their original EDD, with almost 50\% being discharged home around 4 weeks before this date. ${ }^{14}$ Manktelow also showed that infant LOS varies between neonatal units, so using local data may be helpful. ${ }^{11}$

Building on work from McMaster Children's Hospital, Canada, ${ }^{15}$ and using an extensive Delphi process with neonatologists, neonatal nurses and parents, we developed a UK parent pack (Train-to-Home) aimed at supporting parents' preparedness to take their baby home. Use of the Train-to-Home encourages parents to participate in their baby's care from an early stage, to develop a fuller understanding of their baby's needs and the physiological maturation needed before babies can be discharged. The pack is parent centred and provides a practical means of improving communication between staff and parents throughout the baby's hospital stay. By improving parents' self-confidence to care for their baby at home, we anticipated facilitating earlier discharge and reducing emergency or out-of-hours service use after discharge.

Neonatal care is an expensive and limited health resource with prematurely born infants occupying the majority of neonatal hospital bed-days. ${ }^{16}$ The average LNU cost in the UK is over $£ 13000$ for each very low birthweight baby (birth weight $<1500 \mathrm{~g}$, which is the mean birth weight at 30 weeks' gestation). Any increase in parental confidence to care for their infant could reduce their LOS, and possibly reduce healthcare resource use after discharge, making potentially significant healthcare savings. ${ }^{17}$

\section{AIM}

The specific aims of the study were to investigate whether introducing the parent-centred neonatal discharge package (Train-to-Home) increased parental confidence in caring for their infant (self-efficacy), reduced infants' length of hospital stay and reduced healthcare resource use after discharge from hospital.

\section{TRAIN-TO-HOME INTERVENTION}

Soon after admission to the neonatal unit, an accurate estimate of when the baby is likely to be discharged from hospital is provided, based on the locally derived 50th-75th centiles for LOS for each gestation. The discharge date range is displayed on a laminated train which has five labelled carriages: breathing, feeding, growth, temperature and sleeping (figure 1). Using agreed criteria, parents change the carriage window sticker colour from red to yellow and then green to indicate the stage of preparedness for discharge home (figure 2). Parents are also given gestation-specific leaflets with questions linked to the five windows of the train to discuss with staff (figure 3) to help them understand their baby's progress and needs. Each week, the discharge date range narrows as the baby matures and a smaller range of dates is displayed as the baby approaches being ready for discharge. The Train-to-Home intervention was developed for use with all infants of gestational ages between 27 and 33 weeks in the target LNUs.



Figure 1 Train-to-Home. 


\section{STAFF Train-to-Home - Explanatory notes for nurses \& doctors}

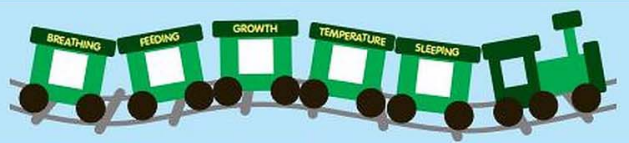

BREATHING

FEEDING

GROWTH

TEMPERATURE

SLEEPING

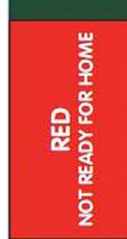

Any of these:

- On a Ventilator

- Breathing fast (more than 90 breaths per minute)

- CPAP and more than $30 \%$ oxygen

- $A s^{*}$ and $\mathrm{Bs}^{*}$ needing bagging in the past 24 hours

- IV caffeine

Any of these:

- CPAP and less than $30 \%$ oxygen

- Less than 90 breaths per minute

- Off CPAP less than 4 days

- Low flow oxygen

- $A s^{*}$ and $B s^{*}$ needing stimulation or repositioning only

Any of these:

- In air

- Off CPAP more than 4 days

- Stable in low flow oxygen

- Occasional $\mathrm{As}^{*}$ and $\mathrm{B} \mathrm{s}^{*}$ needing minimal stimulation

- Oral caffeine

All of these:

- In air (no added oxygen)

- No As* and Bs*

- Off caffeine for at least 5 days

- Stable in low flow oxygen if going home on oxygen

and parents have been trained in its use

$\mathrm{As}^{*}$ and $\mathrm{Bs} \mathrm{s}^{*}=$ short periods of stopping breathing (apnoea) and heart rate falling (bradycardia)

\begin{tabular}{|c|c|c|c|}
\hline $\begin{array}{l}\text { Any of these: } \\
\text { - No feeds by mouth or tube, or only } \\
\text { very small feeds } \\
\text { - All or most of feeds intravenously } \\
\text { - Not yet coping with feeds (more than } \\
50 \% \text { of each feed not absorbed) }\end{array}$ & $\begin{array}{l}\text { Any of these: } \\
\text { - Losing weight } \\
\text { - Weight } \\
\text { more than } \\
10 \% \text { below } \\
\text { birthweight }\end{array}$ & $\begin{array}{l}\text { Any of these: } \\
\text { - Unstable } \\
\text { temperature } \\
\text { - In "servo" incubator } \\
\text { - Incubator } \\
\text { temperature } \\
\text { above } 33^{\circ} \mathrm{C}\end{array}$ & $\begin{array}{l}\text { Any of these: } \\
\text { - Sleeping on the } \\
\text { front to help } \\
\text { breathing } \\
\text { - Receiving medicine } \\
\text { to make baby } \\
\text { comfortable }\end{array}$ \\
\hline $\begin{array}{l}\text { Any of these: } \\
\text { - Coping with increasing feeds } \\
\text { - Less than half of feeds intravenously } \\
\text { - Occasional feeds not absorbed } \\
\text { - Changing from gastric tube }\end{array}$ & $\begin{array}{l}\text { Any of these: } \\
\text { - Not yet gaining } \\
\text { weight } \\
\text { - Gaining } \\
\text { weight for less } \\
\text { than } 3 \text { days }\end{array}$ & $\begin{array}{l}\text { Any of these: } \\
\text { - Stable temperature } \\
\text { - Incubator } \\
\text { temperature } \\
\text { below } 33^{\circ} \mathrm{C} \\
\text { - Out of incubator } \\
\text { for short periods }\end{array}$ & $\begin{array}{l}\text { Any of these: } \\
\text { - Not yet sleeping } \\
\text { on the back all of } \\
\text { the time } \\
\text { - Awake periods } \\
\text { are short }\end{array}$ \\
\hline $\begin{array}{l}\text { Any of these: } \\
\text { - More than } 80 \% \text { of feeds by breast or } \\
\text { bottle } \\
\text { - All feeds by breast, bottle or gastric } \\
\text { tube }\end{array}$ & $\begin{array}{l}\text { All of these: } \\
\text { - Gaining } \\
\text { weight for } 3 \\
\text { days or more }\end{array}$ & $\begin{array}{l}\text { Any of these: } \\
\text { - Temperature } \\
\text { stable and in } \\
\text { normal cot } \\
\text { - In "hot cot" }\end{array}$ & $\begin{array}{l}\text { Any of these: } \\
\text { - Sleeping on the } \\
\text { back all of the time } \\
\text { - Awake for all breast } \\
\text { or bottle feeds }\end{array}$ \\
\hline $\begin{array}{l}\text { All of these: } \\
\text { - Full feeds by breast or bottle } \\
\text { - If going home on tube feeds: stable } \\
\text { on tube feeds and parents trained in } \\
\text { tube feeding }\end{array}$ & $\begin{array}{l}\text { All of these: } \\
\text { - Gaining } \\
\text { weight for } 3 \\
\text { days or more }\end{array}$ & $\begin{array}{l}\text { All of these: } \\
\text { - Temperature } \\
\text { stable and in } \\
\text { normal cot }\end{array}$ & $\begin{array}{l}\text { All of these: } \\
\text { - Awake for all feeds } \\
\text { - Sleeping on the } \\
\text { back all of the time }\end{array}$ \\
\hline
\end{tabular}

Figure 2 Explanation of the window colours on the Train-to-Home.

\section{METHODS}

\section{Study design and population}

Parents of infants born between 27 weeks 0 days and 33 weeks 6 days were recruited in four large LNUs in South West England. Two of the units had associated level 1 units to which some infants were transferred before going home. Parents were recruited during two 11-month periods (phase 1: October 2012-August 2013 and phase 2: October 2013-August 2014) before and after the introduction in the LNUs of the Train-to-Home (with parent pathways). For the research study, infants with major congenital anomalies or with mothers under 16 years were not recruited. Parental assent was sought by the LNU nurses and consent gained by a study researcher.

\section{Outcome measures}

Demographic and clinical information was collected by the researchers for all participating infants. Both parents were asked to complete a validated standardised measure, the Perceived Maternal Parenting Self-Efficacy (PMP S-E $)^{18}$ tool, at three time points to measure perceived parental self-confidence when caring for their infant: soon after their baby's admission to the LNU, shortly before discharge home and 8 weeks after discharge.
A short healthcare resource use data collection tool was developed for parents to record all healthcare contacts for the baby, from which data were collected at telephone follow-up 4 and 8 weeks after discharge. Qualitative data were collected from parents 8 to 10 weeks following discharge by semi-structured telephone interviews exploring their experiences of the unit and perceptions of the intervention. All data were anonymised before analysis. Focus groups were also held to explore the views of nursing staff, and telephone interviews conducted with senior medical staff from all LNUs. Parent interviews and nursing staff focus groups were audio recorded, transcribed verbatim and analysed using thematic methods facilitated by the qualitative package NVivo.

Statistical analysis was performed using IBM SPSS Statistics V.21 and Stata V.13. For proportional data, $\chi^{2}$ tests were used to $n-1$ degrees of freedom. A test of normality on continuous data was conducted using the Shapiro-Wilk test and observing the $\mathrm{Q}-\mathrm{Q}$ plots. The Mann-Whitney U test was used for non-parametric data, which were described using medians and IQRs. Resource use data in volume units were combined with price and unit cost information from published sources ${ }^{19}$ to estimate costs per item in $£$ sterling using 2014 prices. All cost variables were named and defined. 
A

27-30 WEEKS GESTATION

Baby's name

Parent Train-to-Home leaflet

These are some questions to ask the staff to help you to understand your baby's progress and needs.

\begin{tabular}{|c|c|c|c|c|c|c|}
\hline & BREATHING & FEEDING & GROWTH & TEMPERATURE & SLEEPING & How can I help? \\
\hline & $\begin{array}{l}\text { Does my baby need help } \\
\text { with breathing? } \\
\text { What are desat's, } \\
\text { brady's, and apnoeas? } \\
\text { (sometimes called ABC's) } \\
\text { How can I help my baby } \\
\text { with breathing? } \\
\text { What position makes my } \\
\text { baby's breathing easiest? } \\
\text { Does my baby still need } \\
\text { help with breathing? How } \\
\text { can I tell? }\end{array}$ & $\begin{array}{l}\text { How can I feed my baby? What } \\
\text { happens if my baby cannot have } \\
\text { milk to start with? } \\
\text { What are the advantages of } \\
\text { breast milk? } \\
\text { How can I express my milk? } \\
\text { How and where do I store my } \\
\text { expressed milk? } \\
\text { Why is my baby fed through } \\
\text { a tube? Can I help with tube } \\
\text { feeding? } \\
\text { When can I have a kangaroo } \\
\text { care cuddle with my baby? } \\
\text { When will my baby be able to } \\
\text { suck and swallow milk? }\end{array}$ & $\begin{array}{l}\text { Why is my baby weighed } \\
\text { and measured? } \\
\text { Can I see my baby's } \\
\text { growth chart? } \\
\text { What do the lines on the } \\
\text { growth chart mean? } \\
\text { How often will my baby } \\
\text { be weighed? } \\
\text { Why will my baby's weight } \\
\text { go down before it goes } \\
\text { up? } \\
\text { Why is head } \\
\text { circumference important? }\end{array}$ & $\begin{array}{l}\text { Mum and Dad - have you } \\
\text { both had a cuddle with } \\
\text { your baby? } \\
\text { How can I keep my } \\
\text { baby warm when I am } \\
\text { touching them? } \\
\text { What about skin to skin / } \\
\text { kangaroo care? } \\
\text { How do I know my baby } \\
\text { is warm enough? } \\
\text { Is my baby warm enough } \\
\text { under phototherapy } \\
\text { lights? }\end{array}$ & $\begin{array}{l}\text { Why does my baby sleep } \\
\text { a lot of the fime? Why } \\
\text { does my baby not know } \\
\text { day and night? } \\
\text { Why do the staff disturb } \\
\text { my baby when they are } \\
\text { sleeping? } \\
\text { Why do we cover the } \\
\text { incubator? }\end{array}$ & \\
\hline $\begin{array}{l}\text { N } \\
\text { 前 } \\
\text { 了 }\end{array}$ & $\begin{array}{l}\text { How is my baby now? } \\
\text { Maybe needing some } \\
\text { oxygen? } \\
\text { How can I tell when } \\
\text { my baby's breathing is } \\
\text { getting better? }\end{array}$ & $\begin{array}{l}\text { What happens if my baby does } \\
\text { not tolerate feeds? } \\
\text { How am I doing with expressing } \\
\text { my milk? } \\
\text { Have I seen a breastfeeding } \\
\text { advisor yet? } \\
\text { How long can I store my breast } \\
\text { milk for? }\end{array}$ & $\begin{array}{l}\text { Do we have 'weigh' days? } \\
\text { Why is my baby weighed } \\
\text { so often? } \\
\text { How is my baby doing? }\end{array}$ & $\begin{array}{l}\text { Is the incubator } \\
\text { temperature being furned } \\
\text { down? } \\
\text { Can we bring in our own } \\
\text { clothes for our baby? }\end{array}$ & $\begin{array}{l}\text { How do I know when my } \\
\text { baby needs to sleep? } \\
\text { Does my baby have a } \\
\text { sleep cycle and what } \\
\text { does it mean? } \\
\text { Can I read a bedtime } \\
\text { story to my baby? }\end{array}$ & \\
\hline
\end{tabular}

Developed by CCAH Bristol, 2015

$\mathrm{B}$

\section{7-30 WEEKS GESTATION}

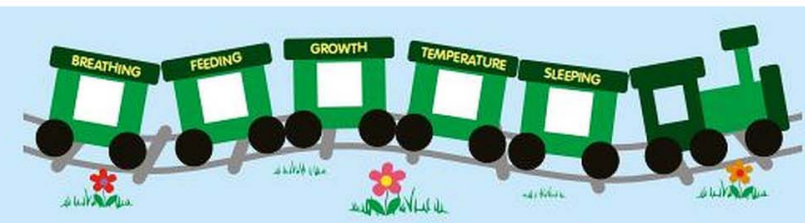

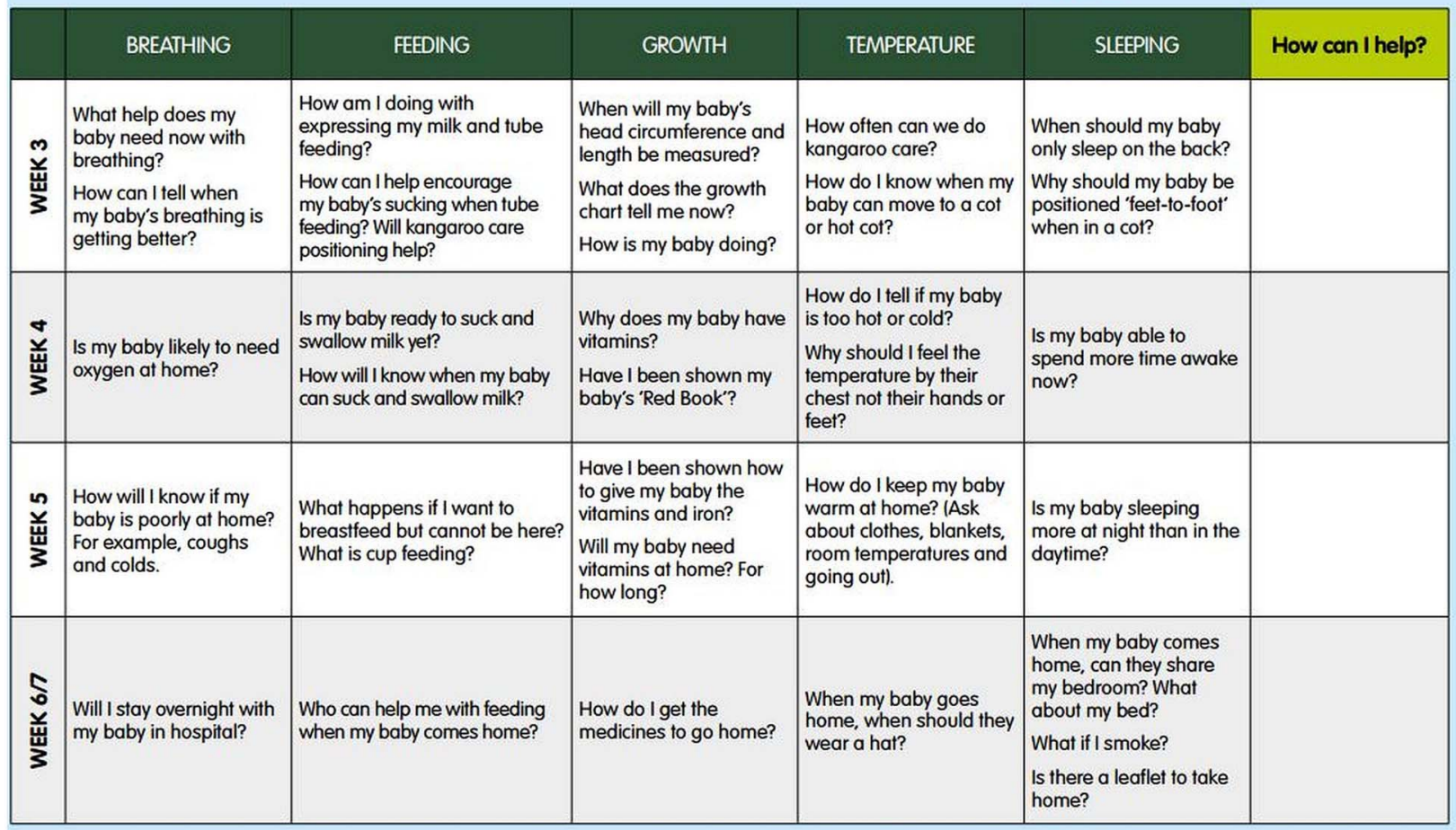

Figure 3 Parent Train-to-Home leaflet for 27-30 weeks' gestation infants.

$4 \quad$ Ingram JC, et al. BMJ Open 2016;6:e010752. doi:10.1136/bmjopen-2015-010752 


\section{RESULTS}

A total of 245 families participated in the study, 128 families in phase 1 and 117 families in phase 2 as shown in figure 4 . There were no significant demographic differences between infants and their families in the two phases as shown in tables 1 and 2. They were well matched for infant sex, gestation, birth weight, socioeconomic status, maternal conditions and breast versus bottle feeding. There was no difference in overall severity of illness or prevalence of cardiorespiratory or infective conditions between the groups, but metabolic, endocrine, gastroenterological and neurological problems were more common in infants in phase 1 as shown in table 3 .
Table 4 shows the overall median maternal PMP S-E scores in phases 1 and 2 at baseline, discharge and 8 weeks after discharge. The scores were not significantly different between the phases. The median improvement in individual mothers' scores between baseline and discharge home was slightly higher in phase 2 than in phase $1(+14 \mathrm{vs}+11)$, but this was not statistically significant (table 5). Similar findings were seen in the paternal PMP S-E scores. The improvements in maternal PMP S-E scores (from baseline to 8 weeks post discharge) were slightly, but not significantly, greater in LNUs in which staff fully engaged with the intervention as was apparent from their reported attitudes in the qualitative interviews.

\section{Recruitment}
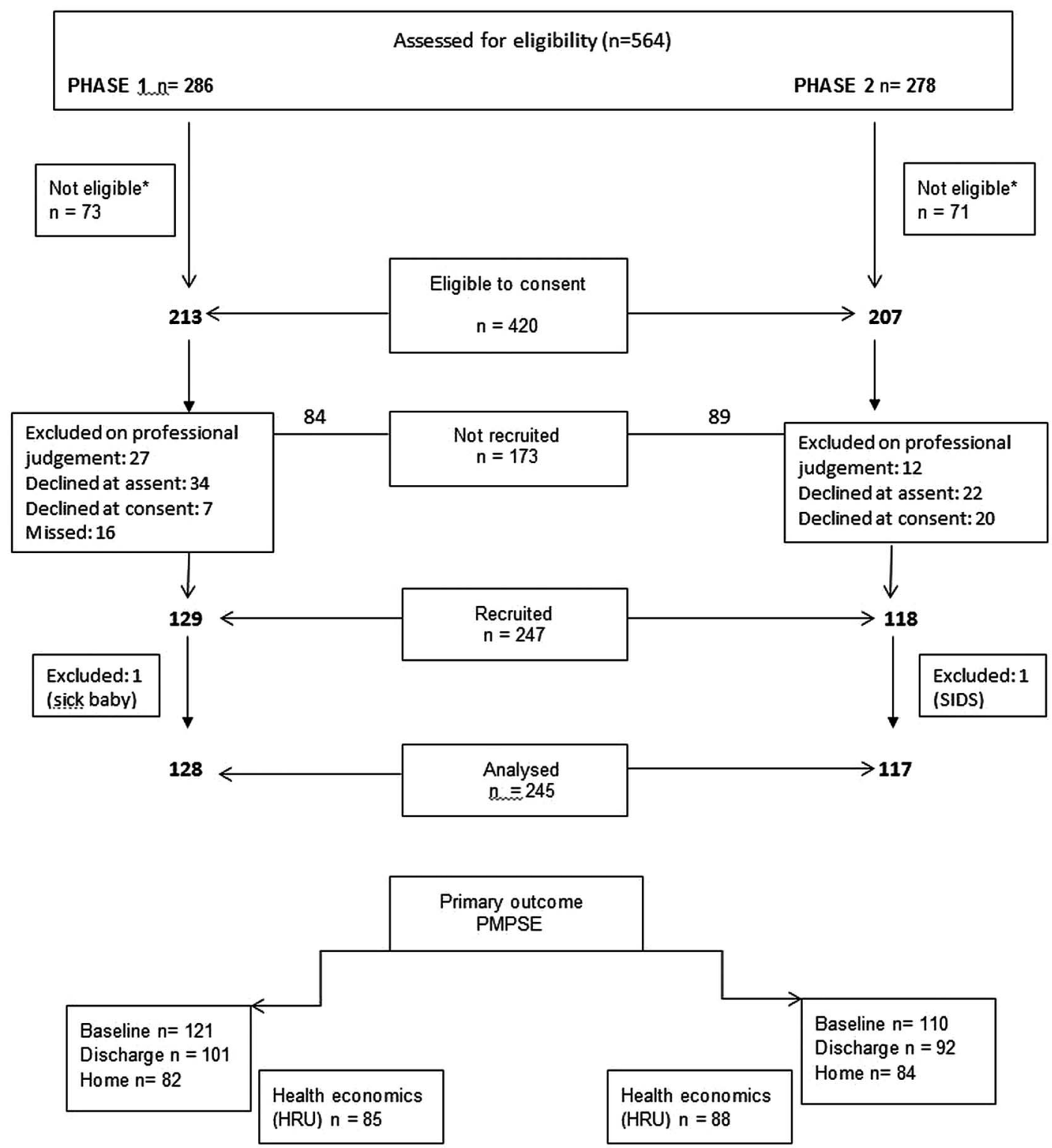

*Reasons for non- eligibility as per protocol: transfer; language problems; abnormality; triplets; out of area; age

Figure 4 Train-to-Home study recruitment diagram. 
Table 1 Infant characteristics

\begin{tabular}{|c|c|c|c|c|c|c|}
\hline \multirow[b]{2}{*}{ Characteristic } & \multirow[b]{2}{*}{ Group of interest } & \multicolumn{2}{|l|}{ Phase 1} & \multicolumn{2}{|l|}{ Phase 2} & \multirow[b]{2}{*}{$p$ Value } \\
\hline & & $\mathrm{n} / \mathrm{N}$ & $(\%)$ & $\mathrm{n} / \mathrm{N}$ & $(\%)$ & \\
\hline Gender & Male & $64 / 128$ & (50) & $62 / 117$ & (54) & 0.64 \\
\hline \multirow[t]{2}{*}{ Twin } & Yes & $16 / 128$ & (13) & $25 / 117$ & (21) & 0.06 \\
\hline & Units & Mean & $(\mathrm{N}, \mathrm{SD})$ & Mean & $(\mathrm{N}, \mathrm{SD})$ & p Value \\
\hline Birth weight & $\mathrm{kg}$ & 1.70 & $(128,0.50)$ & 1.65 & $(114,0.45)$ & 0.44 \\
\hline Gestational age & Weeks/days & 31 weeks 5 days & (128, 13 days) & 31 weeks 4 days & (117, 12 days) & 0.59 \\
\hline
\end{tabular}

The length of hospital stay in phase 1 (median 28 days, IQR 19.5-43.5) was not significantly different ( $\mathrm{p}=0.32$ ) from phase 2 (median 32 days, IQR 20-46). Almost $75 \%$ of infants were discharged home on or before the initially estimated Train-to-Home discharge dates. More infants in phase 2 were discharged home being mixed fed with breast milk and formula and fewer were exclusively formula fed (table 6).

Cost analysis of healthcare after discharge is based on 173 infants, 85/128 in phase 1 and 88/117 in phase 2, for whom sufficient information was provided (response rates of $66 \%$ in phase 1 and $75 \%$ in phase 2, respectively). There were significantly more attendances at emergency departments (EDs) by infants in phase 1 than in phase 2 ( 31 vs 20 , respectively; $\mathrm{p}=0.03$ ), with an associated significantly higher estimated cost in phase 1 than phase 2 ( $£ 3400$ vs $£ 2200$, respectively; $p=0.03$ ). There was no difference between phases 1 and 2 in the number of hospital re-admissions, or hospital outpatient appointments attended by the infants after discharge, and no difference in primary care attendances (table 7).

Results from the qualitative interviews with 37 parents and 24 staff are reported in detail in a separate paper (Ingram in preparation). Parents were overwhelmingly positive about the 'Train-to-Home' package and reported feeling better prepared for home in phase 2 than phase 1. Most found the Train-to-Home helpful in showing them visually that their baby was progressing and described feelings of being given hope and feeling in control. Mothers, fathers and siblings enjoyed using it. Medical and nursing staff generally agreed that the intervention materials were helpful in explaining a baby's physiological progress to parents, but some nursing staff had concerns that the estimated discharge dates were too optimistic. The materials were introduced over a 6-week period which was not long enough to embed the materials into each LNU, and without this period of normalisation, some staff were uncertain about using the package. However, staff in one unit were particularly positive about the Train-to-Home intervention and were keen for it to continue.

\section{DISCUSSION}

There was a small but significant reduction in out-of-hours ED visits and associated costs after the introduction of the Train-to-Home intervention. This was particularly notable in view of an increase in ED attendances nationally over this period, which coincided with the introduction of the ' 111 out-of-hours' service, which encouraged more callers to attend ED. There was no significant difference in the changes in PMP S-E scores between the two phases of the study; however, the change was slightly greater and parents reported feeling more confident in phase 2. PMP S-E scores increased between admission and discharge of the babies in both study phases, indicating improved parental self-efficacy.

Table 2 Family demographics

\begin{tabular}{lllll}
\hline Characteristic & Group of interest & $\begin{array}{l}\text { Phase 1 } \\
\text { n/N (\%) }\end{array}$ & $\begin{array}{l}\text { Phase 2 } \\
\text { n/N (\%) }\end{array}$ & p Value \\
\hline Mother has partner & Yes & $112 / 124(90)$ & $108 / 112(97)$ & 0.06 \\
Maternal ethnicity & British & $109 / 119(92)$ & $98 / 106(93)$ & 0.18 \\
& Other white* & $2 / 119(1.7)$ & $5 / 106(4.7)$ & $(2 \mathrm{df})$ \\
\hline & Othert & $8 / 119(6.7)$ & $3 / 106(2.8)$ & p Value \\
\hline Maternal age & Units & Mean (N, SD) & Mean (N, SD) & 0.98 \\
Paternal age & Years & $30.7(120,5.7)$ & $30.7(111,5.9)$ & 0.46 \\
Deprivation score & Years & $33.2(77,6.4)$ & $32.5(101,6.8)$ & 0.36 \\
\hline Maternal ethnicity: *British, Irish and any other white; tIndian, Pakistani, Caribbean, African, any other black and other. &
\end{tabular}


Table 3 Infant medical conditions

\begin{tabular}{|c|c|c|c|c|c|}
\hline \multirow[b]{2}{*}{ Medical conditions } & \multicolumn{2}{|c|}{ Phase 1} & \multicolumn{2}{|c|}{ Phase 2} & \multirow[b]{2}{*}{ p Value } \\
\hline & $\bar{n} / \mathrm{N}$ & (\%) & $\bar{n} / \mathbf{N}$ & $(\%)$ & \\
\hline Cardiorespiratory conditions & $46 / 128$ & $(36)$ & $39 / 117$ & (33) & 0.67 \\
\hline Infections & $26 / 128$ & (20) & $25 / 117$ & (21) & 0.84 \\
\hline Metabolic, endocrine, gastroenterological & $28 / 128$ & (22) & $12 / 117$ & (10) & 0.01 \\
\hline Neurological & $6 / 128$ & (4.7) & $0 / 117$ & (0) & $0.03^{*}$ \\
\hline
\end{tabular}

*Using Fisher's exact test.

The predicted discharge dates helped parents to prepare for home. The ways that staff engaged with the materials when communicating with them helped them feel more confident, as well as having something visual to show their baby's progress and stage of physiological readiness. The questions in the leaflets encouraged parents to ask appropriate questions in a timely fashion to improve their knowledge and understanding. Monitoring compliance was difficult to measure but staff feedback and attitudes expressed in the interviews indicated that staff engagement was different between the units.

Others have shown that a risk factor for increased use of health services is the parents' perception that their prematurely born infant is vulnerable. ${ }^{6}$ Parents' concerns evolve as they move from the neonatal unit to home, and these may be addressed by providing timely discharge information, as was available through our parent pathway leaflets, and early anticipatory guidance to help build parental confidence as they move towards taking their baby home. ${ }^{6}$

There was no significant change in LOS in the LNU, although more than half the infants went home at least 3 weeks before the EDD in both phases. During phase 2, all the LNUs were working towards gaining full WHO/ UNICEF Baby Friendly Initiative accreditation (http:// www.unicef.org.uk/BabyFriendly) and were therefore encouraging and supporting mothers to go home breast feeding, as reflected by the increased proportion of infants receiving some breast milk at discharge in phase 2. Breastfeeding is more difficult for preterm babies and is often a reason for a longer stay while mothers and babies learn how to breastfeed.

Medical and nursing staff considered the Train-to-Home package fitted well with the NHS discharge planning initiative, but some nursing staff were reluctant to engage fully, expressing concern that the estimated discharge dates were too optimistic. These findings may reflect the limited time available within the study for effective implementation and cascade training of nursing staff. Discharge planning has been shown to work best when it is mutually shared by neonatal unit teams and families, so it is important to find ways of enhancing this process. ${ }^{20}$

The need for neonatal units to develop a more family-orientated approach to care has been highlighted in recent years. In a survey of neonatal family-centred policy and practice in the UK, Redshaw and Hamilton ${ }^{10}$ found considerable variation between neonatal units. They recommended the development of parent-friendly policies to provide a more positive neonatal experience for families. The Train-to-Home package gives parents clear information about their baby's physiological progress which helps them to understand their baby's needs and promotes positive relationships with staff as they discuss progress on a daily basis. These are the fundamental elements of 'family-centred' care. Recently, others have explored mothers' ${ }^{12}$ and nurses' ${ }^{21}$ perceptions of family-centred neonatal care. Finlayson et $a l^{12}$ found little to support family-centred care practice in NICUs and emphasised the importance of improving staff-mother interactions and facilitating mothers' opportunities to be their baby's primary caregiver. Trajkovski et $a l^{21}$ identified that nurses need ongoing organisational support, guidance and education to assist them in delivering family-centred care effectively and the Train-to-Home pack appears to do this.

We are not aware of any other studies that have systematically attempted to assess the impact of a neonatal family-centred care intervention on parental self-efficacy or use of ED post-discharge for moderately preterm infants and suggest that the Train-to-Home can contribute to family-centred care, when staff engage with the approach.

Table 4 Median maternal PMP S-E scores at baseline, discharge and at home 8 weeks following discharge

\begin{tabular}{|c|c|c|c|c|c|c|c|}
\hline \multirow[b]{2}{*}{ When measured } & \multicolumn{3}{|c|}{ Phase 1} & \multicolumn{3}{|c|}{ Phase 2} & \multirow[b]{2}{*}{ p Value } \\
\hline & $\overline{\mathbf{N}}$ & Median & IQR & $\overline{\mathbf{N}}$ & Median & IQR & \\
\hline Baseline & 121 & 60.0 & $54.0-69.5$ & 110 & 59.0 & $54.0-67.0$ & 0.33 \\
\hline Discharge & 101 & 70.0 & $61.5-76.5$ & 92 & 69.0 & $64.0-74.8$ & 0.77 \\
\hline At home & 82 & 74.0 & $66.0-79.0$ & 84 & 74.0 & $70.3-78.0$ & 0.52 \\
\hline
\end{tabular}

PMP S-E, Perceived Maternal Parenting Self-Efficacy. 
Table 5 Median change in individual maternal self-efficacy scores from baseline to discharge and from baseline to 8 weeks after discharge home

\begin{tabular}{llll}
\hline $\begin{array}{l}\text { Increase in maternal } \\
\text { self-efficacy }\end{array}$ & $\begin{array}{l}\text { Phase 1 } \\
(\mathbf{n}=128)\end{array}$ & $\begin{array}{l}\text { Phase 2 } \\
(\mathbf{n}=117)\end{array}$ & $\mathbf{p ~ V a l u e}$ \\
\hline Baseline to discharge & +7 & +8 & 0.60 \\
Baseline to at home & +11 & +14 & 0.10 \\
\hline
\end{tabular}

Limitations of the study include the lack of time for implementing the Train-to-Home intervention which meant that some staff were not confident in using the family-centred approach to discharge planning. The quasi-experimental study design (before and after) was also a limitation but was felt to be the most appropriate design for implementing a complex intervention in neonatal care. The 'before and after' design meant that the intervention and any changes in outcome measures were not randomised between units, but we found no significant differences in the infant or maternal demographics between the two study periods. Our study was also limited to infants of 27-33 weeks' gestation based in four LNUs. In the future, it would be important to implement the package on a network-wide basis to ensure equity so that infants transferred between units would all be using similar discharge planning packages. It also needs to include the wider range of gestational ages cared for in neonatal units so that staff can use it for all infants.

Although our initial primary outcome measure (PMP S-E score) did not show any significant differences between the groups, the improvement in preparedness for discharge home reported by the parents and the measured reduction in ED attendances with associated cost reduction suggest the intervention had significant benefits. This approach to educating and involving parents in the care and needs of preterm babies in hospital has potential value and warrants further study and more widespread adoption.

\begin{tabular}{|c|c|c|c|}
\hline & $\begin{array}{l}\text { Phase } 1 \\
(n=128)\end{array}$ & $\begin{array}{l}\text { Phase 2 } \\
(n=117)\end{array}$ & p Value \\
\hline $\begin{array}{l}\text { Length of stay } \\
\text { (median) }\end{array}$ & $\begin{array}{l}28 \text { days } \\
\text { (IQR 19.5-43.5) }\end{array}$ & $\begin{array}{l}32 \text { days } \\
\text { (IQR 20-46) }\end{array}$ & 0.32 \\
\hline $\begin{array}{l}\text { Feeding on } \\
\text { discharge }\end{array}$ & $\begin{array}{l}\text { Breast } \\
\text { feeding=44\% } \\
\text { Bottle } \\
\text { feeding=35\% } \\
\text { Mixed } \\
\text { feeding=22\% }\end{array}$ & $\begin{array}{l}\text { Breast } \\
\text { feeding=44\% } \\
\text { Bottle } \\
\text { feeding=26\% } \\
\text { Mixed } \\
\text { feeding=31\% }\end{array}$ & $0.13(2 \mathrm{df})$ \\
\hline $\begin{array}{l}\text { Type of milk } \\
\text { at discharge }\end{array}$ & $\begin{array}{l}\text { Breast }=57 \% \\
\text { Formula }=24 \% \\
\text { Both }=20 \%\end{array}$ & $\begin{array}{l}\text { Breast }=62 \% \\
\text { Formula }=19 \% \\
\text { Both }=20 \%\end{array}$ & 0.65 \\
\hline
\end{tabular}

Table 7 Health economic outcomes

\begin{tabular}{llll}
\hline & $\begin{array}{l}\text { Phase 1 } \\
(\mathbf{n = 8 5})\end{array}$ & $\begin{array}{l}\text { Phase 2 } \\
(\mathbf{n = 8 8})\end{array}$ & $\mathbf{p}$ Value \\
\hline $\begin{array}{l}\text { Attendances } \\
\text { at ED }\end{array}$ & 31 & 20 & 0.03 \\
$\begin{array}{l}\text { Cost of ED } \\
\text { attendances }\end{array}$ & $£ 3400 /$ patient & $£ 2200 /$ patient & 0.03 \\
$\begin{array}{l}\text { Re-admission } \\
\text { inpatient days }\end{array}$ & 78 days & 85 days & 0.78 \\
$\begin{array}{l}\text { Outpatient } \\
\text { appointments }\end{array}$ & 115 & 117 & 0.34 \\
\hline $\begin{array}{l}\text { ED, emergency department. } \\
\text { R }\end{array}$ & &
\end{tabular}

Author affiliations

${ }^{1}$ School of Social and Community Medicine, University of Bristol, Bristol, UK ${ }^{2}$ Faculty of Health and Applied Sciences, University of the West of England, Bristol, UK

${ }^{3}$ Faculty of Life Science and Education, University of South Wales,

Pontypridd, UK

${ }^{4}$ Department of Population Health, NPEU, University of Oxford, Oxford, UK

${ }^{5}$ South West Neonatal Network, Bristol, UK

${ }^{6}$ Southmead Hospital, North Bristol NHS Trust, Bristol, UK

Acknowledgements The authors would like to thank all the parents and neonatal staff in the four local neonatal units (LNUs) in Bath, Exeter, Taunton and Swindon who were involved in the study. They are very grateful for the valuable contributions from members of the Parent Advisory Group, Clinical Advisory Group and Trial Steering Group. They also thank McMaster Children's Hospital, Canada, for permission to adapt their concept of the discharge train design for use in the UK.

Disclaimer The views and opinions expressed here are those of the authors and do not necessarily reflect those of the HS\&DR programme, NIHR, NHS or the Department of Health.

Contributors $\mathrm{JCl}$ contributed to the original study design, directed the project and supervised project team members jointly with PF, helped develop the intervention materials and led the qualitative investigations and analyses and contributed to data interpretation. She wrote the first draft of the paper and approved the final version of the manuscript. JEP contributed to the original study design, developed the health economic measures, supervised data entry of health economic data, conducted the health economic analyses and contributed to data interpretation. She contributed to the draft paper and approved the final version of the manuscript. PSB contributed to the original study design, supervised data cleaning and conducted quantitative statistical analyses. He contributed to the draft paper and approved the final version of the manuscript. DP contributed to the original study design and analysis of qualitative interviews. He contributed to data interpretation and approved the final version of the manuscript. MR contributed to the original study design, advised on the qualitative analyses, contributed to data interpretation and approved the final version of the manuscript. SM contributed to the original study design, helped develop the intervention materials, recruited parents to the study, conducted and assisted with analysis of qualitative interviews with parents. She approved the final version of the manuscript. HB helped develop the intervention materials and led the implementation of the interventions. She approved the final version of the manuscript. LB recruited parents to the study, conducted and assisted with analysis of qualitative interviews with parents. She approved the final version of the manuscript. CR contributed to the original study design and was a member of the project management group. She approved the final version of the manuscript. DJ supervised data collection and input, conducted telephone follow-up of parents and contributed to data interpretation. She approved the final version of the manuscript. PJF led the original study design and development of the intervention and teaching materials. He contributed to data interpretation, the draft paper and approved the final version of the manuscript. 
Funding The project was funded by the National Institute for Health Research (NIHR) Health Services and Delivery Research programme (project number $11 / 1015 / 09)$

Competing interests None declared.

Ethics approval Ethical permission was granted by the NRES Committee London-City \& East in June 2012: 12/L0/0944.

Provenance and peer review Not commissioned; externally peer reviewed.

Data sharing statement Data collected were specific to the particular units in which the study was carried out and related to the specific intervention; thus, data sharing would not be appropriate or of use to others.

Open Access This is an Open Access article distributed in accordance with the terms of the Creative Commons Attribution (CC BY 4.0) license, which permits others to distribute, remix, adapt and build upon this work, for commercial use, provided the original work is properly cited. See: http:// creativecommons.org/licenses/by/4.0/

\section{REFERENCES}

1. UK Office for National Statistics. 2011

2. Department of Health. Toolkit for High-Quality Neonatal Services. 2009 Contract No: 297621.

3. Harijan P, Boyle EM. Health outcomes in infancy and childhood of moderate and late preterm infants. Semin Fetal Neonatal Med 2012;17:159-62.

4. Ralser E, Mueller W, Haberland C, et al. Rehospitalization in the first 2 years of life in children born preterm. Acta Paediatr 2012;101:e1-5.

5. Brett J, Staniszewska S, Newburn M, et al. A systematic mapping review of effective interventions for communicating with, supporting and providing information to parents of preterm infants. BMJ Open 2011;1:e000023.

6. Garfield CF, Lee Y, Kim HN. Paternal and Maternal Concerns for their very low-birth-weight infants transitioning from the NICU to home. J Perinat Neonatal Nurs 2014;28:305-12.

7. Hesselink $\mathrm{G}$, Flink $\mathrm{M}$, Olsson $\mathrm{M}$, et al. Are patients discharged with care? A qualitative study of perceptions and experiences of patients, family members and care providers. BMJ Qual Saf 2012;21(Suppl 1) i39-49.
8. Bastani F, Ali Abadi T, Haghani H. Effect of family-centred care on improving parental satisfaction and reducing readmission among premature infants: a randomised controlled trial. J Clin Diagn Res 2015;9:SC04-8.

9. Cleveland LM. Parenting in the neonatal intensive care unit. $J$ Obstet Gynacol Neonatal Nurs 2008;37:666-91.

10. Redshaw M, Hamilton K. Family centred care? Facilities, information and support for parents in UK neonatal units. Arch Dis Child Fetal Neonatal Ed 2010;95F365-8.

11. Manktelow B, Draper ES, Field C, et al. Estimates of length of neonatal stay for very premature babies in the UK. Arch Dis Child Fetal Neonatal Ed 2010;95:F288-292.

12. Finlayson K, Dixon A, Smith C, et al. Mothers' perceptions of family centred care in neonatal intensive care units. Sex Reprod Healthc 2014;5:119-24.

13. Forsythe PL, Maher R, Kirchick C, et al. SAFE Discharge for infants with high-risk home environments. Adv Neonatal Care 2007;7:69-75; quiz 76-7.

14. Ingram J, Blair PS, Powell J, et al. Preparing for home: increasing parental knowledge, understanding and confidence in caring for their preterm infant before and after discharge home. Neonatal Society Summer meeting, 2015. http://www.neonatalsociety.ac.uk/meetings/ 2015 summer abstracts.pdf

15. Gaal B, Blatz S, Dix J, et al. Discharge planning utilising the discharge train: improved communication with families. Adv Neonatal Care 2008:8:42-55

16. Rose C, Ramsay, L, Leaf A. Strategies for getting preterm infants home earlier. Arch Dis Child 2008;93:271-3.

17. Petrou S, Khan K. Economic costs associated with moderate and late pre-term birth: primary and secondary evidence. Semin Fetal Neonatal Med 2012;17:170-8.

18. Barnes CR, Adamson-Macedo EN. Perceived Maternal Parenting Self-Efficacy (PMP S-E) tool: development and validation with mothers of hospitalized preterm neonates. J Adv Nurs 2007;60:550-60.

19. Curtis L. The unit costs of health and social care. Kent: PSSRU, 2014.

20. McGrath JM. Strategies to support the transition to home. J Perinat Neonatal Nurs 2012;26:8-9.

21. Trajkovski S, Schmied V, Vickers M, et al. Neonatal nurses perspectives of family-centred care: a qualitative study. J Clin Nurs 2012;21:2477-87. 